\title{
Attitude Of Teachers Towards Use Of English Language As A Medium Of Instruction In Secondary Schools In Republic Of Tanzania: A Pragmatic Perspective Of Community Secondary Schools In Arusha District
}

\author{
Kipng'etich E. J Kirui
}

\section{Ahmed Osman}

\section{Lyimo Naisujaki}

\begin{abstract}
The purpose of this study was to establish the attitude of teachers towards the use of English as a language of instruction in Community Secondary Schools in Arusha District Tanzania. Despite the government initiatives, the achievement in Certificate of Secondary School Education Examination (CSEE) has been declining especially in the community secondary schools. The study attempted to answer the research question, what is the attitude of teachers towards the use of English as a language of instruction in Community Secondary Schools in Arusha District Tanzania? The study was conducted using descriptive survey in 26 Community Secondary Schools in Arusha Region Tanzania. Data was collected from 257 teachers selected randomly, 26 heads of schools and 1 District Education Officer purposely selected. Context, Input, Process and Product (CIPP) Model by Stufflebeam guided the study. Data collection was done through questionnaire and interviews. Descriptive statistics in terms of frequencies, mean scores, percentages and standard deviations were used to analyze quantitative data. Qualitative data was organized into themes as emerging from the field. The study established that limited competence in English as medium of instruction is a determinant in low academic achievement among students in Community Secondary Schools in Arusha District Tanzania. In order to increase students' achievement, it is recommended that the Government of Tanzania should re-orientate its language policy in schools to enhance English competency among learners in secondary schools.
\end{abstract}

Key words: Community secondary schools, English as language of instruction.

ADEA
AED
BEST
BRNEd
CSEE
EFA
ESDP
ETP
LOI
MDG
NECTA

\section{ABREVIATIONS/ ACRONYMS}

Association for the Development of Education in Africa

Academy for Education Development

Basic Education Statistics of Tanzania

Big Results Now in Education

Certificate of Secondary Education Examination

Education for All

Education Sector Development Program

Education Training Policy

Language of Instruction

Millennium Development Goals

National Examinations Council of Tanzania 


$\begin{array}{ll}\text { NGO } & \text { Non-Governmental Organization } \\ \text { NSGRP } & \text { National Strategy for Growth and Reduction of Poverty } \\ \text { PRT } & \text { Pupil -Teacher Ratio } \\ \text { SEDP } & \text { Secondary Education Development Plan } \\ \text { SEMP } & \text { Secondary Education Master Plan } \\ \text { TCU } & \text { Tanzania Commission for Universities } \\ \text { TIE } & \text { Tanzania Institute of Education } \\ \text { TTC } & \text { Teacher Training Colleges } \\ \text { UNESCO } & \text { United Nations Educational, Scientific and Cultural Organization } \\ \text { URT } & \text { United Republic of Tanzania } \\ \text { USAID } & \text { United States Agency International Development }\end{array}$

BACKGROUND TO THE STUDY

In Tanzania, Secondary Education occupies a pivotal role in the functioning of the economy and the education system itself. Experience shows that, the majority of the people in both the private and public sectors are expected to be secondary education leavers. The whole Primary Education system relies on teachers who are a product of the Secondary Education system. Candidates of higher and Tertiary education and Training are products of the Secondary Education system. This is the essence of being pivotal (URT, 2010).

Since 2001, the Tanzanian Government had taken many initiatives to reform its Primary and Secondary school Education sectors to observe its pivotal role in education. These reforms include implementation of Primary Education Development Program (PEDP) from 2002 to 2006 and Secondary Education Development Plan (SEDP) starting in 2004 all focusing in the Tanzania development strategies on combating ignorance, disease and poverty in line with the National Vision 2025 (Sumra and Rajani, 2006). The PEDP 2002-2006 raised the enrolment rate in Primary education from 59 per cent in 2000 to 97 per cent in 2007 (World Bank, 2008). This created a social demand for and even an expectation of transition to secondary education (UNESCO, 2007).

In 2004, the Government of Tanzania launched its Secondary Education Development Plan (SEDP) aiming significantly to renovate the Secondary Education system throughout the country. SEDP was formulated in line with the development of ward/Community based Secondary schools. The goal was to ensure more access and equity of participation across geographical, gender, disadvantaged group, and the marginalized among the community. Such a critical plan was to curb the substantial increased number of pupils enrolled in Primary schools, thereby creating an upward demand for increased access to Secondary Education (Kambuga, 2013). In 2005, nearly 124,884 students were enrolled in Forms 1-6 and 1,602752 in 2012. By any measures these are large enrolment increases over a short period of time (BEST, 2013). 
Table 1

Academic Performance in Certificate of Secondary Education Examinations (CSEE) by Divisions, 2008-2012

\begin{tabular}{ccccccccc}
\hline Year & \multicolumn{9}{c}{$\begin{array}{c}\text { Division (in \%) } \\
\text { Totals I- } \\
\end{array}$} & I & II & III & $\begin{array}{c}\text { III } \\
\text { IV }\end{array}$ & Pass & $\begin{array}{c}\text { Fail } \\
\text { Total No of Candidates } \\
\text { Examined }\end{array}$ \\
\hline $\mathbf{2 0 0 8}$ & 3.5 & 6.4 & 16.8 & $\mathbf{2 6 . 7}$ & 56.9 & 83.6 & $\mathbf{1 6 . 3}$ & 163,855 \\
$\mathbf{2 0 0 9}$ & 1.9 & 4.4 & 11.6 & $\mathbf{1 7 . 9}$ & 54.7 & 72.5 & $\mathbf{2 7 . 5}$ & 248,336 \\
$\mathbf{2 0 1 0}$ & 1.5 & 2.8 & 7.1 & $\mathbf{1 1 . 4}$ & 38.9 & 50.4 & $\mathbf{4 9 . 6}$ & 352,840 \\
$\mathbf{2 0 1 1}$ & 1.1 & 2.4 & 6.5 & $\mathbf{1 0 . 0}$ & 43.6 & 53.6 & $\mathbf{4 6 . 4}$ & 339,330 \\
$\mathbf{2 0 1 2}$ & 0.9 & 2.8 & 5.9 & $\mathbf{9 . 5}$ & 33.5 & 43.1 & $\mathbf{5 6 . 9}$ & 397,222 \\
\hline
\end{tabular}

Source: Basic Education Statistics of Tanzania (BEST, 2013).

Despite the Tanzanian government initiatives, since 2001 the status of Secondary School Education had not been stable which had led to low academic achievement in National Form Four Examinations results. For example, the proportion of students passing with divisions 1, 2 and 3 has been declining since 2008 and reached its critical point in 2012 as can be evidenced in Table 1. (BEST, 2013).

In the light of the above scenario this study therefore, examined the attitude of teachers towards the use of English as a language of instruction in secondary schools.

In Tanzania the curriculum medium of instruction in Primary Schools is Kiswahili then abruptly it switches to English at Secondary School level. In real fact, the vast majority of public Primary School leavers develop little confidence in English and many cannot string together a simple paragraph. Consequently, they are unable to follow what is taught or written in English in Secondary School, and this may contribute to low academic achievement. Also the enrolment rate to public/government Secondary Schools has increased tremendously with more students expected to join Community Secondary Schools every year. For example, enrolment of Form 1 to 4 increased from 1,293,691 in 2009 to 1,504,711 in 2013 (BEST, 2013).

While acknowledging the government initiatives in providing quality education and increasing access to Secondary School Education, the academic achievement of the students in Community Secondary Schools are still becoming poor.

\section{STATEMENT OF THE PROBLEM}

In recent years, students' academic achievement in the CSEE in Tanzania has been declining, especially in the Community Secondary Schools. This decline in academic achievement raised a number of questions on the parents and government about what might be the reasons for low academic achievement and how it could be addressed. For example the proportion of students passing with divisions 1, 2 and 3 has been declining since 2008 and has reached its critical point in 2012 which was $9.5 \%$ as shown earlier.

This variation implies that there could be school specific determinants of low academic achievement of students. Hence, it is important to find out what can be the determinants contributing to low academic achievement among Community Secondary School students so 
that the information can be used to influence the curriculum planners, policy makers and even budgeting in the education sector and other educational stake holders.

In the light of the above scenario this study isolated the attitude of teachers towards the use of English as a language of instruction as one of the possible reason of low academic performance in Community Secondary Schools.

\section{PURPOSE OF THE STUDY}

The purpose of this study was to assess the attitude of teachers towards the use of English language as a medium of instruction in Community Secondary Schools in Arusha District Tanzania.

\section{OBJECTIVES OF THE STUDY}

In order to achieve the purpose of the study, the main objective of the study was to establish the attitude of teachers towards the use of English as a language of instruction in Community Secondary Schools in Arusha District Tanzania.

\section{SIGNIFICANCE OF THE STUDY}

Low academic achievement in Form Four National Examinations in Tanzania has become a national concern raising anxiety among parents, students and other educational stakeholders. Hence, any attempt directed towards coming up with a solution to this problem will be encouraged by all stakeholders. Therefore, the findings of this study are expected to provide new knowledge on how to address the problem of low academic achievement among students studying Community Secondary Schools in Arusha District.

\section{LIMITATIONS OF THE STUDY}

The research was carried out in the Ordinary Level Community Secondary Schools in Arusha District Council. Hence, this may limit the ability of the researcher to generalise the findings for the country as a whole. However, the study was diligent in use of random sampling.

\section{THEORETICAL FRAMEWORK}

This study based on the Model of Evaluation developed by Stufflebeam (1971) cited in Frye and Hemmer (2012) Context, Input, Process, and Product (CIPP) Model. Stufflebeam's model provides a means for generating valuable information to fulfil the intended objective of this study. The study objective is explained in the input evaluation aspect. Input evaluation assesses alternative means for achieving the intended goals and objectives of the program to help decision makers choose the best optimal means. It asks the question, "How should it be done?" and identifies procedural designs and educational strategies that will most likely achieve the desired results (Zhang et al, 2011). Process evaluation aspect in this study monitors the processes to ensure that the means are actually being implemented and to make the necessary modifications, for this study it includes the issues of English language as a medium of instruction as a means for the implementation of curriculum in Secondary Schools. In Product evaluation, which compares actual ends with intended ends and leads to a series of recycling decisions, in this study product evaluation is expected to bring about good academic achievement in Community Secondary Schools in Arusha District Tanzania as implied by Glatthorn (1987). 


\section{LITERATURE REVIEW}

In the Tanzania Education Training Policy document (1995), the medium of instruction is set to be English language, which is a challenge to both teachers and students in implementing curriculum in secondary schools (Senkoro, 2004; Qorro, 2006). In Tanzania medium of instruction at primary schools is Kiswahili then abruptly it switches to English at secondary school level. In real fact, the vast majority of public primary school leavers develop little confidence in English and many cannot string together a simple paragraph. Consequently, they are unable to follow what is taught or written in English in secondary schools, and this contributes to poor learning which may affect the academic achievement of secondary school education in Tanzania.

When a student in a public school advances to secondary school the language of instruction swiftly changes from Kiswahili to English. All subjects except Kiswahili language are taught in English in secondary schools. Little attempt is made to help students make this transition. Apparently, the learning process becomes challenging for most students in secondary schools as the majority of them largely lack a basic command of English language (Qorro, 2006).

In Tanzania, studies by Andersen (1975) and Qorro (2008) show that proficiency in the language of instruction is an important factor in educational performance. The consequence of this is that lack of proficiency in the language of instruction, results in poor academic performance in subjects taught in English. Elsewhere, studies by Cummins $(1979,1981)$ shows that poor proficiency in the language of instruction results in poor academic achievement in other subjects. These findings have been confirmed by studies in Tanzania by Roy-Campbell and Qorro (1987) and Qorro (1999). In other words, when students have a firm grasp of their specialized subjects, that understanding gives them a firm ground on which to build the foundation for learning a second or foreign language, in this case English. However, this firm grasp/understanding, which is central to the quality of education, can only be achieved when teachers and students understand the language of instruction. In Tanzania secondary school classrooms and higher education the language of instruction is not well understood by the majority of teachers and most students, hence may contribute to low academic achievement.

Malekela (2004) acknowledge that, if learners and even teachers are disabled in the language that is used as a medium of instruction, then the learning process cannot take place effectively. In this case, language can simultaneously play conflicting roles in the educational sphere. It can be a factor with holding academic performance of students (Roy-Campbell, 2001). Language of instruction as among the contributing factor to poor academic performance is also supported by Vuzo $(2002 ; 2010)$ who explained that, learners and teachers have difficulties in using the language with adequate proficiency at the secondary schools. Consequently, he pointed that students can fail to answer well questions simply because they fail to understand the question, not because they do not know the answer. Language can affect a learner's ability to interpret instructions and questions. It can also lead to failure to express their ideas appropriately.

Mosha (2014) asserts that, it is language that the business of schooling is still primarily accomplished, whether that be spoken or written. Student academic achievement is a measure of the effectiveness of a teacher. If the learner is handicapped, in the language of instruction, then learning will not take place at all as the educator and the learner will not be communicating on the same situation. Brown (2000) agreed that, one of the key attributes of an effective teacher is lesson clarity consequently can lead to improved academic achievement to the students. Again, Roy- Campbell and Qorro (1997) describe the Language of instruction 
situation as a crisis. They argued that, result of the low proficiency in the language of instruction is that students are tongue tied and teachers' professional confidence is undermined, the final outcome is low academic achievement in tests and examinations.

However contrary ideas from other scholars like Vuzo (2001) argued that, in the primary schools in Tanzania, Kiswahili is used as the Language of instruction (LOI) but the academic achievement is not good, this illustrates the point that language is important but not a sole contributor to quality education. Other factors such as lack of teaching and learning resources, time on task in teaching and learning, teacher commitment, high teacher student ratios should be taken into consideration and can explain why the performance in primary schools is poor despite using a familiar language for instruction.

Likewise, Sumra and Catabaro (2014) show that, the debate on the LOI has primarily focused on the use of English at Secondary level. The current practice of using Kiswahili in Primary Schools for the majority of children and English at Secondary and higher level is creating quality problems at Secondary levels. This would not have been a problem had children in public schools received a good grounding in English. Also Sumra and Catabaro (2014) added that, although passing PSLE, vast majority of children entering Secondary Schools have very low competency in English. This does affect their performance in Secondary Schools. Looking from the students' perspective, all the terminologies they learned and used for seven years of Primary Education in Kiswahili were not of use from day one in Secondary Schools.

However, Sumra and Catabaro (2014) argued that, most of the debate on the use of English appears to be confusing. Confusion is between using English as a medium of instruction and teaching English as a foreign language. No one would argue against teaching English to our students. English is an important language in today's world and all Tanzanian students should learn it and be fluent in it. The issue of language of instruction is totally different; it is using English in classrooms to teach other subjects such as History, Geography, and Biology and so on (Sumra and Catabaro, 2014). Especially when this is done when majority of the students, and of teachers, do not have the required language competency to teach and learn in English. It is well documented that students and teachers in secondary schools have not attained levels of competency required to make English as a language of instruction. Both teachers and students struggle to express themselves in English. A study conducted by Hakielimu (2008) found that Overall, data show that while children's Kiswahili language competencies are generally well developed, English language competencies are poorly developed in both primary and secondary school students. Students had difficulty in reading, writing and translating the language. This is particularly troublesome in case of secondary school students. On entering secondary schools, children not only have to relearn all the terms and concepts in a new language but also to take on a more difficult set of subjects. If the majority of the students in secondary schools are unable to read and understand the language in which they are taught, as our data show, it is difficult to see how their learning can be enhanced.

Therefore, the overall academic achievement of Tanzanian Secondary School students depends on the LOI to a great extent. This study therefore, wants to establish the attitude of teachers towards the use of English as a language of instruction in relation to Community Secondary Schools academic achievement in Arusha District Tanzania. 


\section{Research Design}

\section{RESEARCH DESIGN AND METHODOLOGY}

The present study utilized a descriptive survey research design because this design deals with an in-depth multi-faceted investigation using both quantitative and qualitative methodologies in the examination of the single social phenomenon (Scheerens, 2000). Orodho (2012) asserts that, descriptive survey research design is used in preliminary and exploratory studies to allow researchers to gather information, summarize, present and interpret for the purpose of clarification.

\section{Research Paradigm}

The study employed Mixed Methods or Pragmatic Paradigm with the aim of increasing the credibility and validity of the results by obtaining findings through convergence of different perspectives. The approach gave the opportunity to cross-check data from multiple sources embraced by different paradigms hence to give more detailed and balanced picture of the situation.

\section{Study Population}

The target population for this study consisted of head teachers and teachers from 26 Community Secondary Schools in Arusha District Council and one District Educational Officer. The study sample from the above population was 318 . These are the persons who interact with learners and curriculum more frequently.

\section{SAMPLE AND SAMPLING PROCEDURES}

Simple random and purposive samplings were used to select research respondents. Arusha District has a population of 1049 teachers which was sampled to get a representative to the study. However, to get head teachers and District Educational Officer purposive sampling was employed. The sample size for teachers was based on the guide line proposed by Krejcie \& Morgan (1970). The sample size of 291 teachers from the population of 1049 was determined. The study used the proposed sample size at 95\% confidence level and 5\% margin of error.

\section{Questionnaire}

\section{DATA COLLECTION METHODS}

The questionnaire is one of the most widely used techniques in research for obtaining information from subjects (Kothari, 2002). According to Best and Kahn (2006) a questionnaire is a set of questions dealing with some topic or related group of topics, given to a selected group of individuals for the purpose of gathering data on a problem under consideration. In this study, the questionnaire comprised of open-ended and closed-ended questions. The openended questions enabled the researcher to look critically at a problem by getting divergent views and opinions from the respondents. Closed-ended questions elicited specific information from respondents regarding a matter.

\section{Interview Guide}

This is a guided set of questions administered through oral communication in a face-to-face relationship between a researcher and respondents (Travers, 2004). The advantage of the interview method is that it allows for greater depth than is the case with other methods of data collection. The interviews therefore can help the interviewer to seek clarification and/or confirmation in regard to information obtained through questionnaire. In this study 26 Headmasters/Mistresses and 1 District Education Officer was interviewed. 


\section{Piloting}

Opie (2005) says that the basic purpose of a pilot is to check that the basic aspects of the design and procedure work. A pilot study gives the researcher an idea of what the method will actually look like in operation and what effects (intended or not) it is likely to have. The researcher conducted a pilot study involving 51 teachers from two Secondary schools in Arusha City, which was not to be included in the final sample. Necessary adjustments were made based on the pilot outcome.

\section{Validity Of Instruments}

Cohen et al (2000) defines validity as the degree to which a measuring instrument satisfies the purpose for which it was constructed. It measures how truthful the research results are or the extent to which scores truly reflect the underlying variable of interest. In this study, contentrelated validity of instruments was determined by giving the questionnaire to the supervisors, colleagues in class and other experts in education field to carefully and critically examine and assess the relevance of the items to the objectives of the study. This was done and question items modified so as to collect right instruments.

\section{Reliability Of Instruments}

According to Fraenkel and Norman (2006) reliability is a statistical concept and relates to consistency and dependability consistency of obtaining the same relative answer when measuring phenomena that have not changed. A reliable measuring instrument is one that, if repeated under similar conditions would present the same result or a near approximation of the initial result.

Consequently, a pilot study with 51 respondents who were not part of the study was done before the actual data collection and the researcher used Cronbach's Alpha as a measure of internal consistency. Cronbach's Alpha is a reliability coefficient that indicates how well items in a set are positively correlated to one another (Sekaran, 2003). A value of 0.792 was obtained for the research questionnaire showing that the instrument was reliable.

\section{Ethical Considerations}

All ethical guidelines were adhered to, including briefing participants about the objectives of the study, maintaining anonymity and confidentiality and ensuring that respondents who will participate voluntarily had given full consent.

\section{DATA ANALYSIS, PRESENTATION, INTERPRETATION AND DISCUSSION OF FINDINGS}

The attitude of teachers towards the use of English as a language of Instruction in Community Secondary Schools in Arusha District was determined by five indicators namely, effect of the use of English Language as Medium of Instruction on Students' Academic Achievement, challenges facing the usage of English as Medium of Instruction, students ability to understand when taught in English and English Language as determining factor for low academic achievement.

\section{a. Effects of English Language on Students' Academic Achievement}

Teachers were asked whether English as Medium of Instruction has any effect on students' academic achievement. As Table 2 suggests, majority of teachers registered their feelings that, English as a Language of instruction has some effects on students' academic achievement. 
Table 2

\begin{tabular}{ccc} 
Does the use of English as Language of Instruction Affect Students' & Academic Achievement? \\
\hline Teachers' Response & Frequency & Percentage \\
\hline Yes & 205 & 79.8 \\
No & 44 & 17.1 \\
Neutral & 8 & 3.1 \\
TOTAL & $\mathbf{2 5 7}$ & $\mathbf{1 0 0 . 0}$ \\
\hline
\end{tabular}

Source: Field Data (2016)

Particularly, one of interviewed school heads expressed his deeper feelings that "because language is a tool for sharing knowledge with the students in the classroom, so if the language used is not understood by both teacher and the students, we don't expect to have good performance in their final examinations."

Another head of school added: “Yes, this is really a problem. As students can't express themselves using the language of instruction, they can't even apply the knowledge using the language, and so this shows that there is a big problem." Interview guide further indicated that the root of this problem is in the switch from Kiswahili as medium of instruction in primary schools to English as a language of instruction in secondary schools as expressed:

To me I can say English as a language for instruction in secondary schools may be the major cause of students' failure. As you know, these students at primary school level Kiswahili was the Language of instruction, but when they join secondary school they find themselves into another new language of instruction, again they need to master the language first so that they can use it, so it becomes very difficult to master and apply the language for that short period of time. And remember at primary level English is been taught as a subject, this brings so much confusion not only to students but also teachers (Interviewee 1).

This implies that barriers of English as a language of Instruction is a problem to both teachers and learners. This led to further investigation on specific challenges facing the teachers in the use of the language as medium of instruction.

Through questionnaires, teachers were asked to indicate whether they face challenges in the use of English as a language of instruction in secondary schools. As Table 4.10 indicates, 198 (73.2\%) teachers agreed that they face challenges in the use of English as a language of Instruction in Community Secondary Schools in Arusha District, while only 65 (25.3\%) teachers did not agree. Four teachers (1.6\%) were neutral. This implies that majority of teachers in Community Secondary Schools in Arusha District agreed that they face challenges in the use of English as Medium of Instruction. The most common challenge cited through open-ended data from the questionnaire was learners' limited competence in English Language as Medium of Instruction.

Table 3

Do you face challenges in the use of English as Medium of Instruction?

\begin{tabular}{ccc}
\hline Teachers' Response & Frequency & Percentage \\
\hline Yes & 198 & 73.2 \\
No & 65 & 25.3 \\
Neutral & 4 & 1.6 \\
TOTAL & $\mathbf{2 5 7}$ & $\mathbf{1 0 0 . 0}$ \\
\hline
\end{tabular}

Source: Field Data (2016) 
One teacher for instance asserted that students sometimes fail not because they do not know the answers but simply because of the language barrier. Another teacher commented that English language is an obstacle to students as most of the essay questions are not attempted due to lack of vocabulary in students' heads. This was in harmony with what was indicated during interview schedule where one of the school heads maintained that the use of English as a language of instruction contributes to failures in our school, this is because of poor background in the language of instruction from Primary level, where Kiswahili is the language used and when they join Secondary level they find English as the language of instruction (Interviewee 1).

This is also supported by literature in the work of Sumra and Rajani (2006) who bring to view the fact that the vast majority of public primary school leavers in Tanzania develop little confidence in English and many cannot string together a simple paragraph. Consequently, they are unable to follow what is taught or written in English in secondary school, and this contributes to poor learning which affects the academic achievement of secondary school education in Tanzania. This situation led to further investigation on the effect of English Language on students' academic performance as perceived by teachers.

\section{b. Students Ability to Understand when Taught in English}

A total number of 227 (88.3\%) teachers rejected that their students understand when English is used as a language of Instruction while $5(1.9 \%)$ teachers were neutral.

Table 4

Do Your Students Have Ability to Understand When Taught in English?

\begin{tabular}{ccc}
\hline Teachers' Response & Frequency & Percentage \\
\hline Yes & 24 & 9.3 \\
No & 227 & 88.3 \\
Neutral & 5 & 1.9 \\
TOTAL & $\mathbf{2 5 7}$ & $\mathbf{1 0 0 . 0}$ \\
\hline
\end{tabular}

Source: Field Data (2016)

This implies that majority of teachers (more than three quarters) rejected that their students have ability to understand when English is used as a language of Instruction in classrooms. This is in harmony with the contention of Sumra and Rajani (2006) that the vast majority of Public Primary school leavers develop little confidence in English and many cannot string together a simple paragraph. Consequently, they are unable to follow what is taught or written in English in secondary school, and this contributes to poor learning which affects the academic achievement of Secondary School Education in Tanzania. Studies by Andersen (1975) and Qorro (2008) show that, proficiency in the language of instruction is an important factor in educational performance. This implies that if students are not competent in the language of Instruction, they cannot experience better achievement, and therefore, lack of proficiency in the language of instruction could be a possible determining factor for low academic achievement among students in Community Secondary Schools in Arusha District.

To further determine the place of English Language in teaching-learning transaction, it was necessary to find out about teachers' perception whether English Language is a determining factor for low academic achievement by students under investigation. 


\section{c. English Language and Low Academic Achievement}

It was also necessary to have the view of teacher on the connection between the use of English language and students' low academic achievement. As Table 5 indicates, majority of teachers (76.3) agreed that English as a Language of Instruction is a determining factor for students' low academic achievement. This is in harmony with what has been previously expressed by teachers that incompetence in English Language as a language of Instruction is a major hindrance for students to succeed in their studies.

Table 5

Is English as a Language of Instruction a Determining Factor for Students' Low Academic Achievement?

\begin{tabular}{ccc}
\hline Teachers' Response & Frequency & Percentage \\
\hline Yes & 198 & 76.3 \\
No & 58 & 22.6 \\
Neutral & 3 & 1.2 \\
TOTAL & $\mathbf{2 5 7}$ & $\mathbf{1 0 0 . 0}$ \\
\hline
\end{tabular}

Source: Field Data (2016)

This study established that:

\section{FINDING}

a. Majority of teachers say that English Language has some negative effects on students' academic achievement. This is because students cannot express themselves using the language; they cannot even apply the knowledge taught using the language, and so this shows that, the use of English as a language of instruction contributes to students low academic achievement.

b. Majority of teachers agreed that they face challenges in the use of English as a language of Instruction. The most common challenge cited through open-ended data from the questionnaire and interview guide was learners' limited competence in English as a Language of Instruction. Thus, English as a Language as of instruction is a determinant of low academic achievement in Community Secondary Schools in Arusha District.

\section{CONCLUSIONS OF THE STUDY}

The study sought to assess the role of English language as a determinant of low academic achievement of students in community secondary schools. However, the finding of this study lead to an overall conclusion that, secondary education in Tanzania is facing many challenges which contribute to low academic achievement of students. Mainly, students have limited competence in English Language. The use of English a language of instruction has some negative effects on students' academic achievement since they cannot express themselves and leading to inadequate application of the knowledge taught using the language.

\section{RECOMMENDATIONS OF THE STUDY}

Based on conclusion of this study, the researcher recommends that the MOE should come up with a policy on upgrading of English to enhance competencies in the language among Form One students when they join secondary education. This will increase their level of competence in English language as a language of instruction in secondary schools and make them successful for the rest of their secondary school education journey and thus, reaching highest possible academic achievement. 
Kirui, K. E. J., Osman, A., \& Naisujaki, L. (2017). Attitude Of Teachers Towards Use Of English Language As A Medium Of Instruction In Secondary Schools In Republic Of Tanzania: A Pragmatic Perspective Of Community Secondary Schools In Arusha District. Advances in Social Sciences Research Journal, 4(9) 105-117.

\section{References}

Andersen, R. (1975) 'The Language Factor', occasional paper No. 1, Department of Foreign Basic Education Statistic in Tanzania (BEST) (2012-2013). Ministry of Education and Vocation Training, Dar es Salaam.

Best, W., \& Kahn, J. 2006. Research in education. Boston: Pearson Education Inc.

Brown, H. D. (2000). Principles of language learning and teaching. New Jersey, NJ: Prentice Hall.

Campbell, C. P. (1999) Instructional materials: their preparation and evaluation. Journal of European Industrial Training, 23, 57 - 107.

Cohen, L., Manion, L. \& Morrison, K. (ed.) 2000. Research methodsin education. London: Routledge.

Cummins, J. (1979) 'Cognitive/Academic Language Proficiency, Linguistic Interdependence, the Optimal Age Question and Some Other Matters', Working Papers on Bilingualism, 19, 197-205.

Cummins, J. (1981) 'The Role of Primary Language Development in Promoting Educational Success for Language Minority Students' in Schooling and Language Minority Students: A Theoretical Framework, 3-49.

Fraenkel, J. \& Norman, E. 2006. How to design and evaluate research in education. New educational research: A guide to first-time researchers. London: SAGE Publications.

Frye, A.W. and Hemmer, P. A. (2012). Program evaluation models and related theories: AMEE Guide. In Journal of Medical Teacher. 34, 67.

Glatthorn, A. A. (1987). Curriculum leadership. New York: HarperCollins.

Hakielimu. (2011). Are our Teachers Qualified and Motivated to Teach? A research report on teachers' qualifications, motivation and commitment to teach and their implications on quality education. Dares Salam: Hakielimu.

Kambuga, Y. (2013). The Role of Community Participation in the Ongoing Construction of Ward Based Secondary Schools: Lessons of Tanzania. In International Journal of Education and Research Vol. 1 No. 7.

Kothari, C.R. (2002). Research Methodology: Methods and Techniques. New Delhi: New Age International Publishers.

Malekela, G. (2003). English as a medium of instruction in post-primary education in Tanzania: Is it a fair policy to the learners'? In: Brock-Utne, B., Desai, Z., \& Qorro, M. (eds.). Language of instruction in Tanzania and South Africa. (LOITASA). Dar es Salaam: E\&D Limited.

Mosha, M.A. (2014). Factors affecting students' performance in English Language in Zanzibar Rural and Urban Secondary Schools. In Journal of Education and Practice Vol.5, No.35.

Qorro, M. A. S. (1999) 'A Qualitative Study on the Teaching and Learning of Writing in Tanzania Secondary Schools in Relation to Writing Requirements of Tertiary Education', unpublished Ph.D. Thesis, University of Dar es Salaam.

Qorro, M. A. S. (2006). Does language of Instruction affect quality of Education? Dares sallam: Hakielimu.

Rajani, R. and Sumra, S. (2005). Funding Primary School Education: Conceptual and Measurement Challenges. Dar es Salaam: Adult Education Press.

Roy-Campbell and Qorro, M. (1987) 'A Survey of the Reading Competence in English among Secondary School Students in Tanzania', a Research Report funded by IDRC.

Scheerens, K.(2000). Issues in Social Science Research. Chicago: University of Chicago http://www.interesjournals.org/ER

Sekaran, U. (2003). Research methods for business (4th ed.). Hoboken, New Jew: John Wiley \& Sons.

Stufflebeam, D. L. (1971). The use of experimental design in educational evaluation.Journal of Educational Measurement, 8(4), 267-274.

Sumra, S. and Rajani, R. (2006). Secondary Education in Tanzania: Key Policy Challenges. Dar -es- Salaam: Hakielimu.

Travers, R.M. (2004). An Introduction to Educational Research. New York: Macmillan Publishing. UNESCO (2011). Institute of Statistics. http://www.uis.unesco.org/ 
UNESCO (2007). Experts' consultation on the operational definition of basic education. Paris, France: UNESCO.

URT (United Republic of Tanzania) (2010). Basic Education Statistics in Tanzania (BEST) . Dar es Salaam: Adult Education Press.

Vuzo, M. (2002).'Using English as a Medium of Instruction in Tanzania secondary Schools: Problems and Prospects'. In: Brock-Utne, Desai and Qorro (eds.): LOITASA Research in Progress Dar es Salaam: KAD Associates

Vuzo, M. (2010). Exclusion through Language: A reflection on classroom discourse in Tanzanian Secondary Schools. Papers in Education and Development, 29, 14-36.

World Bank (2008). An Impact Evaluation of World Bank Support to Basic Education in Ghana. Washington D.C.: The World Bank.

Zhang, G., Zeller, N., Griffith R., Metcalf, D., Williams, J., Shea, C., and Misulis, K. (2011). Using the Context, Input, Process, and Product Evaluation Model (CIPP) as a Comprehensive Framework to Guide the Planning, Implementation, and Assessment of Service-learning Programs. Journal of Higher Education Outreach and Engagement, 15, 57. 